\title{
Expression of PD-L1 and SOX2 during rectal tumourigenesis: Potential mechanisms for immune escape and tumour cell invasion
}

\author{
TIM J. MILLER ${ }^{1,2}$, MELANIE J. MCCOY ${ }^{2,3}$, CHRISTINE HEMMINGS ${ }^{1,4}$, \\ BARRY IACOPETTA ${ }^{3}$ and CAMERON F. PLATELL ${ }^{1,2}$
}

\author{
${ }^{1}$ Medical School, University of Western Australia, Crawley, WA 6009; ${ }^{2}$ Colorectal Research Unit, St John of God Subiaco \\ Hospital, Subiaco, WA 6904; ${ }^{3}$ School of Biomedical Science, University of Western Australia, Crawley, WA 6009, Australia; \\ ${ }^{4}$ Department of Anatomic Pathology, Canterbury Health Laboratories, Christchurch 8011, New Zealand
}

Received January 23, 2018; Accepted August 2, 2018

DOI: $10.3892 / 01.2018 .9337$

\begin{abstract}
Immunoediting is defined as a process whereby tumour cells develop the capacity to escape immune cell recognition. Accumulating evidence suggests that cancer stem-like cells (CSCs) have an enhanced capacity to interact with the immune system. The expression of CSCs and immune cell-associated markers has been demonstrated to change with disease progression from premalignant lesions to invasive cancer. The present study investigated the expression of putative CSC and immune cell-associated markers in different stages of progression from dysplasia to invasive malignancy in rectal lesions. Immunohistochemistry was performed for the CSC markers Lgr5 and SOX2 and the immune-associated markers CD8, Foxp3 and PD-L1 in 79 cases of endoscopically-excised rectal lesions, ranging from low grade adenoma (LG) to invasive adenocarcinoma (AdCa). CD8 and Foxp3 expression significantly increased with advances in disease progression [AdCa vs. LG: Odds ratio (OR) 4.33; 95\% confidence interval (CI), 1.16-16.3; $\mathrm{P}=0.03$ and $\mathrm{OR}, 40.5 ; 95 \% \mathrm{CI}, 6.57-249.6$; $\mathrm{P}<0.0001$, respectively]. An increase in programmed death-ligand 1 (PD-L1) expression was also observed with disease progression (OR, 24.0; 95\% CI, 4.23-136.2; $\mathrm{P}=0.0003)$. The expression of sex determining region Y-box 2 (SOX2) did not correlate with disease progression, although an elevated expression was observed in areas with high grade dysplasia. Increased PD-L1 expression may be a mechanism by which tumour cells evade immune recognition, facilitating tumour cell invasion in rectal cancer. The expression of SOX2 in areas with high grade dysplasia may indicate the de-differentiation of tumour cells, or the activation of migration pathways for invasion.
\end{abstract}

Correspondence to: Dr Tim J. Miller, Medical School, University of Western Australia, 35 Stirling Highway, Crawley, WA 6009, Australia

E-mail: timothy.miller@uwa.edu.au

Key words: programmed death-ligand 1, sex determining region Y-box 2, rectal, tumourigenesis, colorectal cancer, cancer stem cell

\section{Introduction}

Colorectal cancer (CRC) is the second most common cancer worldwide (1). It is widely accepted that inactivating mutations in the adenomatous polyposis coli $(A P C)$ gene are the initiating event in the traditional pathway of CRC development, with further accumulation of oncogenic mutations leading to cancer development and progression $(2,3)$. Morphologically normal intestinal crypts containing APC-deficient cells are observed prior to the formation of adenomas (4). This suggests the initiating event in adenoma formation is an $A P C$ mutation in a crypt stem cell that subsequently divides to form all other crypt cells, thereby passing on the APC mutation to daughter cells and eventually leading to the formation of APC-deficient crypts (4). This supports the notion that crypt stem cells are the cell-of-origin in CRC (5).

Normal intestinal stem cells are identified by expression of a membrane receptor named leucine-rich repeat-containing G-protein coupled receptor-5 (Lgr5) (6). This marker may also identify the cell-of-origin in intestinal cancers (5). Expression of Lgr5 increases during progression from normal intestinal cells to adenomas and cancers, suggesting that expansion of crypt stem cells occurs upon tumour formation (7-10). Interestingly, Lgr5 positive $\left(\mathrm{Lgr}^{+}\right)$cells in early adenoma development reside at the luminal surface before migrating towards the basal region of crypts during progression of disease $(9,11)$. Although the majority of intestinal adenomas are thought to originate from $\mathrm{Lgr5}^{+}$cells, $\mathrm{Lgr} 5$ cells also may also develop into early adenomas $(11,12)$.

The transcription factor referred to as sex determining region Y-box 2 (SOX2) is essential for the induction of pluripotency in adult cells (13). SOX2 expression in CRC has been associated with features of 'stemness' and is as a marker of poor prognosis (14-17). Although SOX2 expression in early CRC has not yet been characterised, increased expression has been associated with disease progression in head and neck cancer (18), gynaecological cancers (19) and squamous cell carcinoma of the lung (20).

Both Lgr5 and SOX2 have been described as markers of cancer stem-like cells (CSC), a population of cancer cells with stem cell-like properties such as self-renewal, chemoresistance and enhanced tumourigenicity (21). Accumulating 
evidence suggests that CSC may also have enhanced ability for immune evasion, thus increasing their survival advantage (22). Immune escape has been described as the final stage of the immunoediting process whereby tumours gain the ability to avoid immune recognition, leading to invasive cancer $(23,24)$. Infiltration of the tumour by lymphocytes is a well-established prognostic factor in CRC $(25,26)$. Cell densities for the $\mathrm{T}$ lymphocyte subsets $\mathrm{CD} 8^{+}$cytotoxic $\mathrm{T}$ cells and Foxp3 ${ }^{+} \mathrm{T}$ regulatory (Treg) cells have also been shown to increase with progression of disease (27-29).

The expression of programmed death-ligand 1 (PD-L1) can inhibit $\mathrm{T}$ cell activity and may provide a mechanism for premalignant tumour cells to escape immune recognition (30). PD-L1 can be expressed by both immune cells and tumour cells, and has recently become the target of novel, immune-modulating therapies that antagonise PD-1 signalling to improve tumour-specific immune responses $(31,32)$. The expression of PD-L1 has been found to increase with disease progression in early oral cancer (33) and in respiratory papilloma (34). However, its expression in early CRC has yet to be characterised.

The aim of this exploratory study was to assess expression of the putative CSC markers Lgr5 and SOX2, and the immune cell-related markers CD8, Foxp3 and PD-L1 through the stages of rectal cancer development from low grade adenoma (LG) to invasive cancer, and to investigate any correlation between CSC and immune cell-related markers.

\section{Materials and methods}

Patient selection and ethic approval. Patients who underwent Trans-anal Endoscopic MicroSurgery (TEMS) for resection of benign polyps or early stage carcinoma with no evidence of local spread during the period from November 2006 to April 2014 were identified from our institutional research database. At the time of diagnosis, each case was assessed by a pathologist for the degree of dysplasia and the presence or absence of invasive cancer. This information was used to allocate cases into one of four groups for the purposes of this study: LG, low grade adenoma with high grade areas (LGwHG), high-grade adenoma (HG), and invasive cancer. The study was approved by the St John of God Healthcare (SJ-737) and the University of Western Australia Human Research Ethics Committees (RA/4/1/7278). All patients gave written informed consent for the use of their biological material and health information for research purposes.

Immunohistochemistry (IHC). $4 \mu \mathrm{m}$ sections were cut from selected samples and mounted on positively charged slides for IHC. Staining was performed for the markers Lgr5, SOX2, CD8, Foxp3 and PD-L1. Sections were dewaxed and rehydrated in a graded xylene and ethanol series before performing antigen retrieval in a DakoCytomation laboratory pressure cooker (Dako, Copenhagen, Denmark) at $121^{\circ} \mathrm{C}$ for $6 \mathrm{~min}$. Sections for Lgr5 and SOX2 were submersed in $10 \mathrm{mM}$ sodium citrate retrieval buffer ( $\mathrm{pH}$ 6.0) and sections for CD8, Foxp3 and PD-L1 in CINtec epitope retrieval buffer ( $\mathrm{pH} 9.0$; CINtec Histology kit; Roche Australia, Castle Hill, New South Wales, Australia). Endogenous peroxidase activity and non-specific IgG binding was blocked using Peroxidazed 1 and Background Sniper solutions, respectively (Biocare Medical LLC., Concord, CA, USA). Lgr5 (1:200; MC-1235; MBL International, Woburn, MA, USA) and CD8 (1:100; C8/144B; Dako) primary antibodies were incubated for $30 \mathrm{~min}$ at room temperature. Primary antibodies for SOX2 (1:50; EPR3131; Abcam, Cambridge, MA, USA), Foxp3 (1:100; 236A/E7; Abcam) and PD-L1 (1:100; E1L3N; Cell Signalling Technology, Inc., Danvers, MA, USA) were incubated for one hour at room temperature. The REAL ${ }^{\mathrm{TM}}$ EnVision HRP/DAB staining system (Dako) was used to complete immunostaining for Lgr5, SOX2 and PD-L1. SOX2 and PD-L1 were also incubated with EnVision FLEX Linker prior to secondary antibody application. The MACH-2 Mouse HRP-polymer and Betazoid DAB (Biocare Medical, LLC.) was used for CD8 immunostaining. The MACH-3 Mouse HRP detection system (Biocare Medical, LLC.) was used for Foxp3 immunostaining. All sections were briefly counterstained in Mayer's haematoxylin (Hurst Scientific, Perth, Western Australia, Australia) before dehydration and mounting.

Marker expression analysis. Sections were scanned on a high-resolution scanner (Aperio Scanscope XT; Leica Biosystems, North Ryde, New South Wales, Australia) and manually annotated to ensure the tissue analysed matched the histology type to which samples had been assigned. Image analysis software was then used to quantify marker expression as previously described (Aperio Imagescope version 11) $(35,36)$. Expression of PD-L1 by immune and tumour cells was included in the analysis. Data were reported as cell density (cells $/ \mathrm{mm}^{2}$ ) for SOX2, CD8 and Foxp3 and as percentage of positively staining area for Lgr5 and PD-L1.

Statistical analysis. Correlations between marker expression as continuous variables were analysed using linear regression. Comparisons between expression in each group was assessed using the Kruskal-Wallis test. Categorical variables were created for each marker using median expression values as the cut-off to distinguish low and high expression. As group was a non-binary, ordered outcome variable the associations between groups and categorical expression levels were assessed using multinomial logistic regression with $\mathrm{P}$-values generated using the Wald Chi-squared statistic. $\mathrm{P}<0.05$ was considered to indicate a statistically significant difference. SAS version 9.4 (SAS Institute, Inc., Cary, NC, USA) and Graphpad prism version 7 (GraphPad Software, Inc., La Jolla, CA, USA) were used for statistical analysis.

\section{Results}

Tumour classification. Patient samples were classified into one of four groups based on the level of dysplasia and the invasion status as determined by a pathologist at the time of diagnosis. There were $20 \mathrm{LG}, 18 \mathrm{LGwHG}, 19 \mathrm{HG}$ and 22 cases of adenocarcinoma (AdCa). Of the 57 cases with preinvasive disease (LG, LGwHG or HG), all were considered to contain villous, tubular or tubulovillous architecture. All tumours were localised to the rectum.

Immunohistochemical staining. Lgr5 was predominantly expressed in the cytoplasm of tumour cells with a granulated 
Table I. Median expression and number of cases classified as high for each marker.

\begin{tabular}{|c|c|c|c|c|c|}
\hline Marker & Median & $\mathrm{LG}, \mathrm{n}(\%)$ & LGwHG, n (\%) & $\mathrm{HG}, \mathrm{n}(\%)$ & $\mathrm{AdCa}, \mathrm{n}(\%)$ \\
\hline Lgr5 & $9.84 \%$ & $10(50.0)$ & $10(55.6)$ & $8(42.1)$ & $12(54.5)$ \\
\hline SOX2 & 50.5 cells $/ \mathrm{mm}^{2}$ & $8(40.0)$ & $10(55.6)$ & $9(47.4)$ & $12(54.5)$ \\
\hline CD8 & 293.5 cells $/ \mathrm{mm}^{2}$ & $5(25.0)$ & $9(50.0)$ & $12(63.2)$ & $13(59.1)$ \\
\hline Foxp3 & 194.8 cells $/ \mathrm{mm}^{2}$ & $2(10.0)$ & $7(38.9)$ & $13(68.4)$ & $18(81.8)$ \\
\hline PDL1 & $8.01 \%$ & $2(10.0)$ & $8(44.4)$ & $14(73.7)$ & $16(72.7)$ \\
\hline
\end{tabular}

LG, low grade adenoma; LGwHG, low grade adenoma with high grade areas; HG, high grade adenoma; AdCa, adenocarcinoma; Lgr5, Leucine-rich repeat-containing G-protein coupled receptor-5; SOX2, sex determining region Y-box 2; CD8, cluster of differentiation 8; Foxp3, forkhead box P3; PD-L1, programmed death-ligand 1.
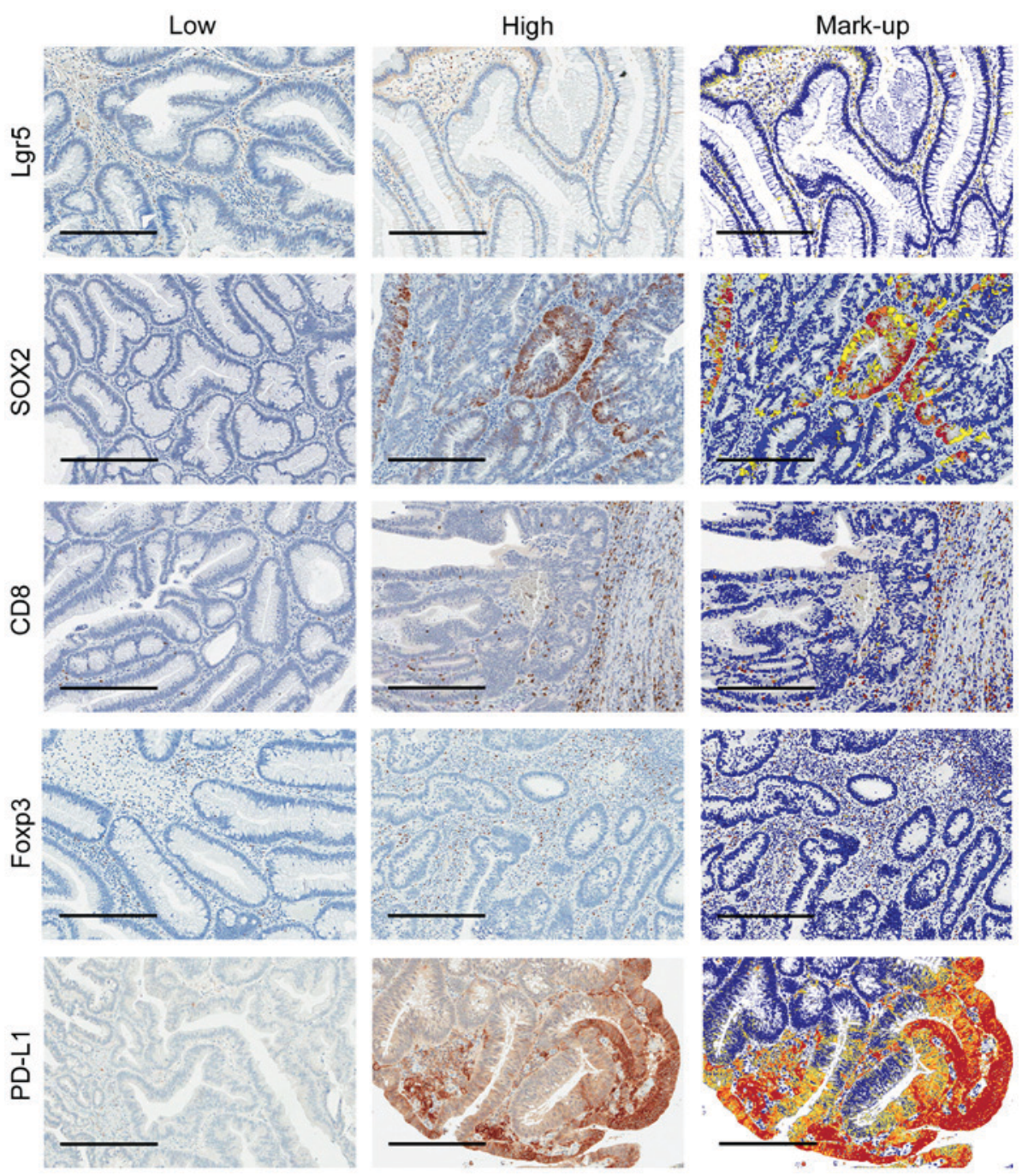

Figure 1. Low and high immunostaining of Lgr5, SOX2, CD8, Foxp3 and PD-L1 with corresponding digital mark-up of high immunostaining images. Representative images (70X) of each marker where blue represents negative staining, yellow weak, orange moderate and red strong staining in digital mark-up images. Scale bars $=300 \mu \mathrm{m}$. Lgr5, Leucine-rich repeat-containing G-protein coupled receptor-5; SOX2, sex determining region Y-box 2; CD8, Cluster of differentiation 8; Foxp3, Forkhead box P3; PD-L1, Programmed death-ligand 1.

appearance. For SOX2 and Foxp3, nuclear expression was primarily observed in tumour cells and in lymphocytes, respectively. Membranous expression on lymphocytes was seen for CD8 and PD-L1 with some stromal and membranous tumour cell expression also seen for PD-L1 (Fig. 1). The median expression level for each marker was used to stratify patients into low and high expression groups (Table I).

Correlations between marker expression. Linear regression was used to assess correlations in marker expression. PD-L1 

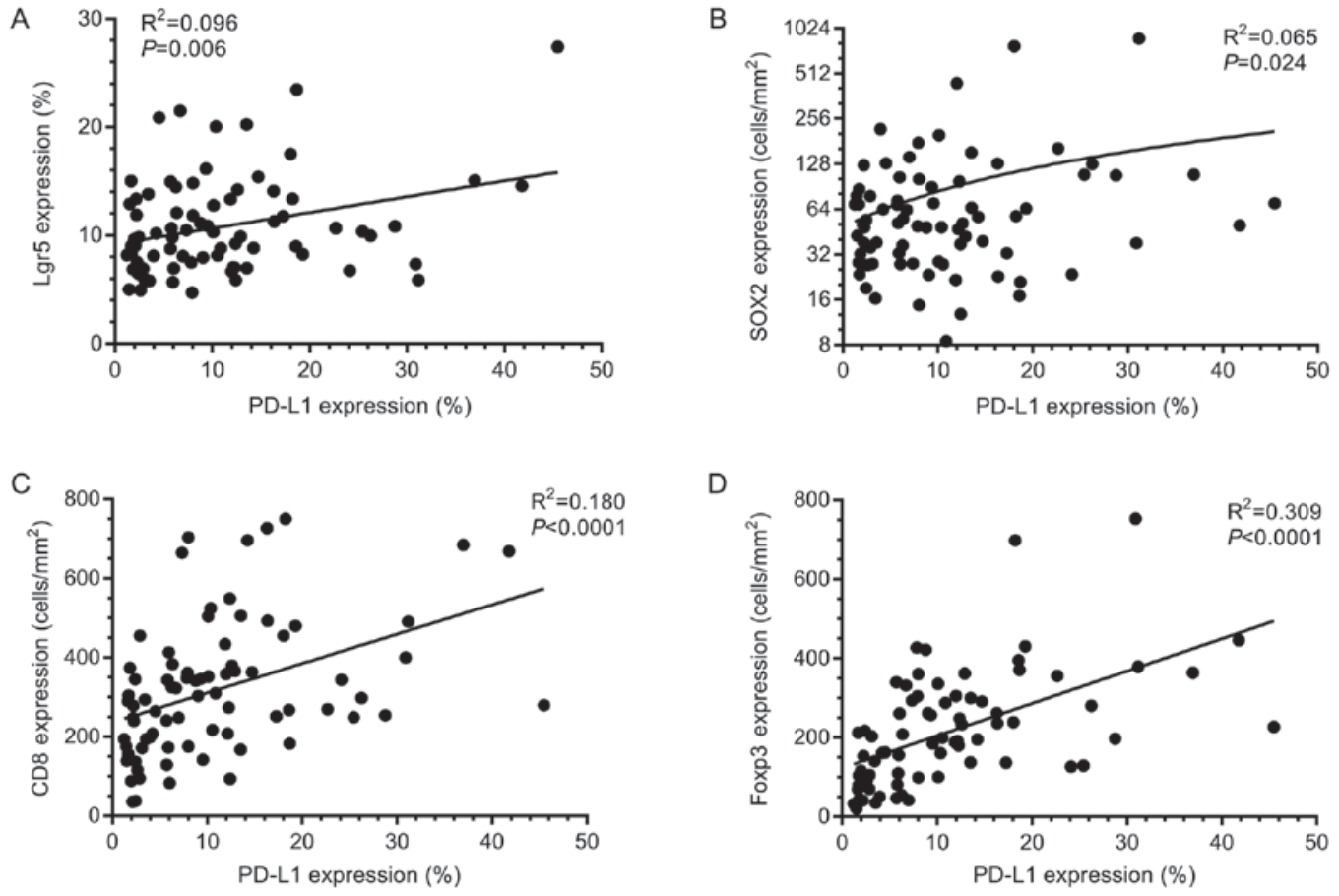

Figure 2. PD-L1 correlates with immune cell and CSC marker expression. Graphical representation of linear regression results assessing correlations between PD-L1 and (A) Lgr5, (B) SOX2, (C) CD8 and (D) Foxp3 expression. Significant correlations were found between PD-L1 expression and all other markers assessed in this study. Lgr5, Leucine-rich repeat-containing G-protein coupled receptor 5; SOX2, sex determining region Y-box 2; CD8, Cluster of differentiation 8; Foxp3, Forkhead box P3; PD-L1, Programmed death-ligand 1.
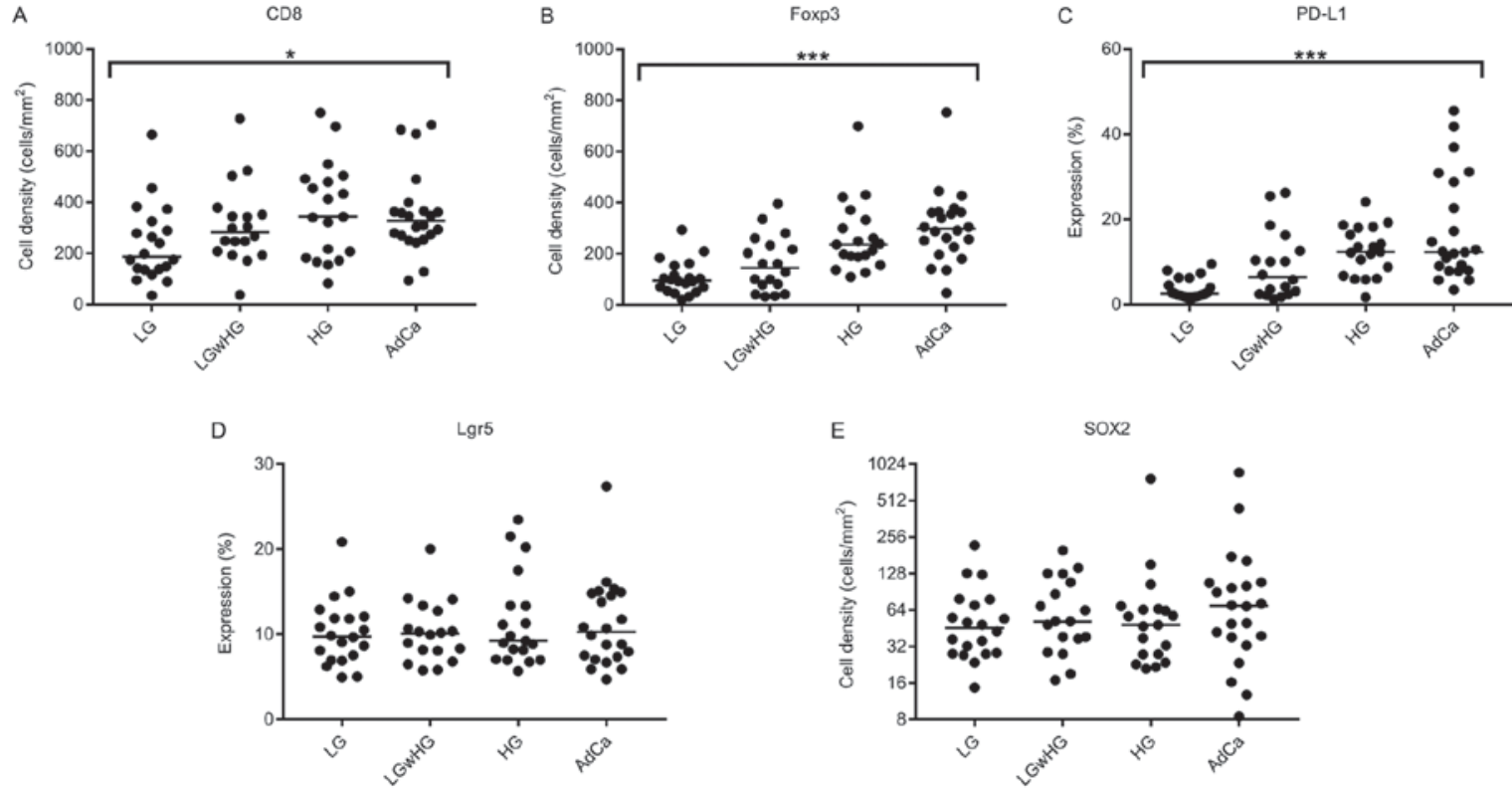

Figure 3. Expression of each marker with progression of disease. Dots represent individual cases within each group for (A) CD8, (B) Foxp3, (C) PD-L1, (D) Lgr5 and (E) SOX2. Bars represent median values. Immune-related marker expression trends upwards with progression of disease. Although not significant, the median expression of SOX2 in the AdCa groups is considerably higher than that observed in other groups. Expression between groups was compared using the Kruskal-Wallis test. ${ }^{*} \mathrm{P}<0.05,{ }^{* * *} \mathrm{P}<0.001$. Lgr5, Leucine-rich repeat-containing G-protein coupled receptor 5; SOX2, sex determining region Y-box 2; CD8, Cluster of differentiation 8; Foxp3, Forkhead box P3; PD-L1, Programmed death-ligand 1.

expression significantly correlated to all other markers studied (Fig. 2). CD8 and Foxp3 expression also demonstrated a highly significant positive correlation $\left(\mathrm{R}^{2}=0.27 ; \mathrm{P}<0.0001\right)$. Expression of Lgr5 and SOX2 demonstrated no significant correlation $\left(\mathrm{R}^{2}=0.0004 ; \mathrm{P}=0.87\right)$ suggesting that different sub-populations of tumour cells are identified by these markers.
Marker expression during disease progression. Kruskal-Wallis tests showed that there was significant difference between the expression of CD8, Foxp3 and PD-L1 with disease progression using expression as a continuous variable (Fig. 3A-C). This was confirmed in multinomial regression analysis using expression as a categorical variable (Table II). 
The expression of Foxp3 and PD-L1 both significantly increased with progression of disease (overall $\mathrm{P}=0.0003$ and $\mathrm{P}=0.0010$ respectively). Compared to $\mathrm{LG}$ adenoma, the greatest increase in expression for Foxp3 was observed in AdCa [odds ratio $(\mathrm{OR})=40.5$; 95\% confidence interval $(\mathrm{CI}), 6.57-249.6$; $\mathrm{P}<0.0001$; Table II]. For PD-L1 expression, the largest increase was observed in $\mathrm{HG}$ adenoma when compared to $\mathrm{LG}$ adenoma (OR=25.2; 95\% CI, 4.24-49.8; $\mathrm{P}=0.0004$; Table II).

Although not significant overall using multinomial regression $(\mathrm{P}=0.089)$, increased expression of $\mathrm{CD} 8$ was nevertheless seen in $\mathrm{HG}$ adenoma $(\mathrm{OR}=5.14 ; 95 \% \mathrm{CI}, 1.30-20.4 ; \mathrm{P}=0.02)$ and $\mathrm{AdCa}(\mathrm{OR}=4.33 ; 95 \% \mathrm{CI}, 1.16-16.3 ; \mathrm{P}=0.03)$.

No significant differences between groups were seen for Lgr5 or SOX 2 expression $(\mathrm{P}=0.84$ and $\mathrm{P}=0.75$, respectively). However, in cases classified as LGwHG, higher SOX2 expression was observed the high grade areas (Fig. 4).

\section{Discussion}

In this exploratory study we assessed expression of the putative CSC markers Lgr5 and SOX2 and the immune cell-related markers CD8, Foxp3 and PD-L1 at different stages of rectal tumourigenesis. Expression of each of the immune cell-related markers increased significantly during progression from LG adenoma to AdCa, but no changes were observed for the CSC markers.

The increased expression of CD8 and Foxp3 in HG adenomas and $\mathrm{AdCa}$ groups found here is consistent with previous reports (27-29) and is suggestive of a tumour-specific immune response attempting to control the progression of disease (expansion of tumour-specific $\mathrm{CD} 8^{+} \mathrm{T}$ cells with concurrent expansion of Foxp3 ${ }^{+}$regulatory T cells). However, a concurrent increase in PD-L1 expression was also observed, particularly in $\mathrm{HG}$ adenoma and $\mathrm{AdCa}$, which may represent an immune escape mechanism. Secretion of interferon- $\gamma$ by $\mathrm{T}$ cells can induce expression of PD-L1 (37), so the increased $\mathrm{T}$ cell infiltrates in the later stages of disease progression observed here may induce PD-L1 expression in tumour cells, potentially permitting tumour cell invasion and the development of AdCa.

The antibody and protocol used here for PD-L1 immunostaining was carefully optimised in-house and has been directly compared to clinically validated protocols (38). However, it is important to note that the analysis method used in this study could not distinguish between tumour and stromal expression of PD-L1, even though it is less subjective than traditional scoring methods. Although assessment of PD-L1 expression to date has generally been limited to tumour cells, there is evidence that immune-cell expression is also clinically relevant in CRC (39-41). Tumour cells may constitutively express PD-L1, or the expression may be induced via $\mathrm{T}$ cell responses (39). The ability to distinguish PD-L1 expression in terms of contribution from the $\mathrm{T}$ cell infiltrate and from tumour cells may provide important information with respect to tumour-specific immune responses. It is also interesting to note that recent findings suggested the $P D-L 1$ gene can be transcriptionally activated by SOX2, thus providing a potential intrinsic mechanism for the induction of PD-L1 expression in tumour cells (42). This is consistent with the present result showing that PD-L1 and SOX2 expression are significantly correlated. 

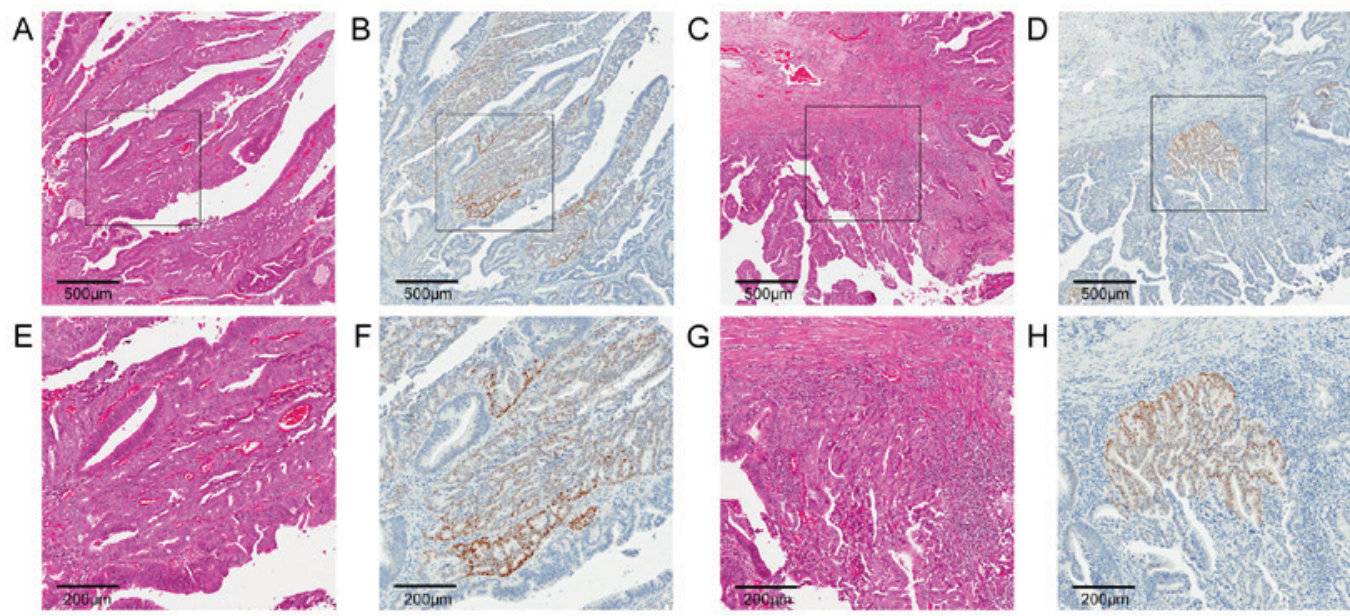

Figure 4. Expression of SOX2 in areas of high grade dysplasia. Representative immunostaining for (B, D, F and H) SOX2 and matched (A, C, E and G) H\&E stains in areas of high grade dysplasia for a case diagnosed as low grade adenoma containing high grade features. Low power images (magnification, $\mathrm{x} 50$ ) of region 1 and 2 (A-D, respectively) with boxes indicating higher power images (magnification, x120)of each region (E-H, respectively) are shown. SOX2 expression is present in high grade areas of low grade adenomas, suggesting a function for SOX2 in tumour cell invasion. Scale bars=500 $\mu \mathrm{m}$ for A-D and $200 \mu \mathrm{m}$ for E-H. Lgr5, Leucine-rich repeat-containing G-protein coupled receptor 5; SOX2, Sex determining region Y-box 2; CD8, Cluster of differentiation 8; Foxp3, Forkhead box P3; PD-L1, Programmed death-ligand 1.

Increased expression of the putative CSC markers CD44, CD133 and Musashi-1 have been correlated with the progression of premalignant disease in gastric cancer (43). In contrast, no significant relationship between CSC marker expression and the progression of rectal cancer was observed in the present study. Other studies have reported increased expression of Lgr5 mRNA using in situ hybridisation (ISH) in LG adenoma and AdCa compared to normal tissue $(7,8)$. Since IHC was used in the present study to assess protein expression, it is possible that poor antibody specificity may explain the discrepant results. Nonetheless, the distribution of Lgr5 expression observed here was consistent with previous reports using $\operatorname{IHC}(9,10)$ and ISH $(7,8)$, with the expression localised primarily to the luminal surfaces in LG adenoma, and heterogeneous expression throughout the crypts at later stages of tumourigenesis.

One explanation for the observed lack of change in SOX2 expression during rectal tumourigenesis may be due to the small sample size. Also, SOX2 expression may have greater relevance for proximal colon cancers with higher expression in right-sided, primary colonic tumours associated with metastatic spread and poorer outcomes (14). Since the samples used in this study were all resected using the TEMS procedure they were all rectal. However, an increase in the median expression of SOX2 was observed in the AdCa group (Fig. 3E). Increased SOX2 expression was also seen in LGwHG where malignant progression may be occurring, as signified by areas of higher grade dysplasia (Fig. 4). This result suggests that SOX2 could play a role in progression of dysplasia by promoting de-differentiation or by promoting cellular migration and invasion. The mechanism underlying SOX2 up-regulation in tumour cells could therefore be relevant as a possible target to inhibit disease progression. Recent evidence has shown that stem-like characteristics of $\mathrm{Lgr}^{+} \mathrm{CSC}$ subsets can be intrinsic to these cells, rather than being induced by stromal signals (44). It is not known whether the stem-like characteristics of SOX2 expressing tumour cells is induced via signals from the stromal microenvironment or if these cells also undergo intrinsic changes independent of external signals. These findings could provide novel insights into the mechanisms of increasing dysplasia and invasion, as well as how tumour cells escape immune recognition in the early stages of tumourigenesis.

No correlation was observed between expression of Lgr5 and SOX2 in this study. This indicates that perhaps these two markers are identifying two different subsets of tumour cells or possibly different CSC subsets. There was also no significant increase in Lgr5 or SOX2 expression with disease progression. As CSC only account for a small minority of tumour cells it is possible that the methods used here could not detect subtle changes in positive CSC marker expression. It is also possible that the functional status of CSC is more clinically relevant than their density. It is important to note that Lgr5 and SOX2 are only thought to identify cancer cells with stem-like potential. Markers of functional CSC have yet to be identified and this warrants further investigation.

Here, we have demonstrated increased expression of the T cell markers CD8 and Foxp3 concurrently with PD-L1 expression during rectal tumourigenesis. To our knowledge, this is the first study to demonstrate elevated expression of PD-L1 in HG adenoma and early AdCa, when compared to LG adenoma in rectal lesions. This may represent a mechanism by which tumour cells avoid T cell-mediated immunity. Another novel finding in this study was that higher SOX2 expression was observed in high grade areas, which could be associated with de-differentiation and cellular migration. However, further investigation is required to determine the exact role of SOX2 expression in rectal tumourigenesis.

\section{Acknowledgements}

The authors would like to thank Mr. Bob Mirzai and Dr Kathy Fuller at the School of Pathology and Laboratory Medicine, University of Western Australia for assistance with sectioning, Ms. Cheryl Penter of St John of God 
Subiaco Hospital for assistance with data collection, and Professor Paul Rigby and Ms. Alysia Hubbard of the Centre for Microscopy, Characterisation and Analysis at the University of Western Australia for assistance with digital slide scanning.

\section{Funding}

Dr Timothy J. Miller was funded by a University Postgraduate Award and a John Clauscen Murray Postgraduate Scholarship. Purchasing of the image analysis software was funded by the Tonkinson Colorectal Cancer Research Fund.

\section{Availability of data and materials}

The datasets used and/or analyzed during the current study are available from the corresponding author on reasonable request, subject to review by the institutional ethics committee.

\section{Authors' contributions}

TJM was involved in the study design, pathological review, performed the laboratory experiments, data analysis and the manuscript review. MJM was involved in the study design and manuscript review. $\mathrm{CH}$ assisted with the pathological review and was involved in the study design and manuscript review. BI was involved in the study design and manuscript review. CFP was involved in the study design and manuscript review.

\section{Ethics approval and consent to participate}

The study was approved by the St John of God Healthcare (SJ-737) and the University of Western Australia Human Research Ethics Committees (RA/4/1/7278). All patients provided written informed consent for the use of their biological material and health information for research purposes.

\section{Patient consent for publication}

All patients provided written informed consent to the publication of research results as part of the consent procedure.

\section{Competing interests}

The authors declare that they have no competing interests.

\section{References}

1. American Cancer Society: Global cancer facts \& figures. 2nd edition. American Cancer Society, Atlanta, GA, 2012.

2. Vogelstein B, Fearon ER, Hamilton SR, Kern SE, Preisinger AC, Leppert M, Nakamura Y, White R, Smits AM and Bos JL: Genetic alterations during colorectal-tumor development. N Engl J Med 319: 525-532, 1988.

3. Fearon ER and Vogelstein B: A genetic model for colorectal tumorigenesis. Cell 61: 759-767, 1990.

4. Fischer JM, Schepers AG, Clevers H, Shibata D and Liskay RM Occult progression by Apc-deficient intestinal crypts as a target for chemoprevention. Carcinogenesis 35: 237-246, 2014

5. Barker N, Ridgway RA, van Es JH, van de Wetering M, Begthel H, van den Born M, Danenberg E, Clarke AR, Sansom OJ and Clevers H: Crypt stem cells as the cells-of-origin of intestinal cancer. Nature 457: 608-611, 2009.
6. Barker N, van Es JH, Kuipers J, Kujala P, van den Born M, Cozijnsen M, Haegebarth A, Korving J, Begthel H, Peters PJ and Clevers H: Identification of stem cells in small intestine and colon by marker gene Lgr5. Nature 449: 1003-1007, 2007.

7. Baker AM, Graham TA, Elia G, Wright NA and Rodriguez-Justo M: Characterization of LGR5 stem cells in colorectal adenomas and carcinomas. Sci Rep 5: 8654, 2015.

8. Jang BG, Kim HS, Kim KJ, Rhee YY, Kim WH and Kang GH: Distribution of intestinal stem cell markers in colorectal precancerous lesions. Histopathology 68: 567-577, 2016.

9. Takeda K, Kinoshita I, Shimizu Y, Matsuno Y, Shichinohe T and Dosaka-Akita H: Expression of LGR5, an intestinal stem cell marker, during each stage of colorectal tumorigenesis. Anticancer Res 31: 263-270, 2011.

10. Becker L, Huang Q and Mashimo H: Immunostaining of Lgr5, an intestinal stem cell marker, in normal and premalignant human gastrointestinal tissue. ScientificWorld Journal 8: 1168-1176, 2008.

11. Choi JW, Kim JK, Choi M, Kim YR and Yun SH: In vivo imaging of Lgr5-positive cell populations using confocal laser endomicroscopy during early colon tumorigenesis. Endoscopy 46: 1110-1115, 2014

12. Davis H, Irshad S, Bansal M, Rafferty H, Boitsova T, Bardella C, Jaeger E, Lewis A, Freeman-Mills L, Giner FC, et al: Aberrant epithelial GREM1 expression initiates colonic tumorigenesis from cells outside the stem cell niche. Nat Med 21: 62-70, 2015.

13. Takahashi K and Yamanaka S: Induction of pluripotent stem cells from mouse embryonic and adult fibroblast cultures by defined factors. Cell 126: 663-676, 2006.

14. Neumann J, Bahr F, Horst D, Kriegl L, Engel J, Luque RM, Gerhard M, Kirchner T and Jung A: SOX2 expression correlates with lymph-node metastases and distant spread in right-sided colon cancer. Bmc Cancer 11: 518, 2011.

15. Lundberg IV, Löfgren Burström A, Edin S, Eklöf V, Öberg Å, Stenling R, Palmqvist R and Wikberg ML: SOX2 expression is regulated by BRAF and contributes to poor patient prognosis in colorectal cancer. PLoS One 9: e101957, 2014.

16. Lundberg IV, Edin S, Eklöf V, Öberg A, Palmqvist R and Wikberg ML: SOX2 expression is associated with a cancer stem cell state and down-regulation of CDX2 in colorectal cancer. BMC Cancer 16: 471, 2016.

17. Ong CW, Chong PY, McArt DG, Chan JY, Tan HT, Kumar AP, Chung MC, Clément MV, Soong R, Van Schaeybroeck S, et al: The prognostic value of the stem-like group in colorectal cancer using a panel of immunohistochemistry markers. Oncotarget 6 : 12763-12773, 2015.

18. Mazibrada J, Longo L, Vatrano S, Cappia S, Giorcelli J, Pentenero M, Gandolfo S, Volante M, dell'Oste V, Lo Cigno I, et al: Differential expression of HER2, STAT3, SOX2, IFI16 and cell cycle markers during HPV-related head and neck carcinogenesis. New Microbiol 37: 129-143, 2014.

19. Hellner K, Miranda F, Fotso Chedom D, Herrero-Gonzalez S, Hayden DM, Tearle R, Artibani M, KaramiNejadRanjbar M, Williams R, Gaitskell K, et al: Premalignant SOX2 overexpression in the fallopian tubes of ovarian cancer patients: Discovery and validation studies. EBioMedicine 10: 137-149, 2016.

20. Yuan P, Kadara H, Behrens C, Tang X, Woods D, Solis LM, Huang J, Spinola M, Dong W, Yin G, et al: Sex determining region Y-Box 2 (SOX2) is a potential cell-lineage gene highly expressed in the pathogenesis of squamous cell carcinomas of the lung. PLoS One 5: e9112, 2010.

21. Kreso A and Dick JE: Evolution of the cancer stem cell model. Cell Stem Cell 14: 275-291, 2014.

22. Bruttel VS and Wischhusen J: Cancer stem cell immunology: Key to understanding tumorigenesis and tumor immune escape? Front Immunol 5: 360, 2014.

23. Dunn GP, Bruce AT, Ikeda H, Old LJ and Schreiber RD: Cancer immunoediting: From immunosurveillance to tumor escape. Nat Immunol 3: 991-998, 2002.

24. Schreiber RD, Old LJ and Smyth MJ: Cancer immunoediting: Integrating immunity's roles in cancer suppression and promotion. Science 331: 1565-1570, 2011.

25. Pagès F, Berger A, Camus M, Sanchez-Cabo F, Costes A, Molidor R, Mlecnik B, Kirilovsky A, Nilsson M, Damotte D, et al: Effector memory $\mathrm{T}$ cells, early metastasis, and survival in colorectal cancer. New Engl J Med 353: 2654-2666, 2005.

26. Galon J, Costes A, Sanchez-Cabo F, Kirilovsky A, Mlecnik B, Lagorce-Pagès C, Tosolini M, Camus M, Berger A, Wind P, et al: Type, density, and location of immune cells within human colorectal tumors predict clinical outcome. Science 313: 1960-1964, 2006. 
27. Maglietta A, Maglietta R, Staiano T, Bertoni R, Ancona N Marra G and Resta L: The immune landscapes of polypoid and nonpolypoid precancerous colorectal lesions. PLoS One 11: e0159373, 2016.

28. Mariani F, Sena P, Pedroni M, Benatti P, Manni P, Di Gregorio C, Manenti A, Palumbo C, de Leon MP and Roncucci L: Th inducing POZ-Kruppel Factor (ThPOK) is a key regulator of the immune response since the early steps of colorectal carcinogenesis. PLoS One 8: e54488, 2013.

29. McLean MH, Murray GI, Stewart KN, Norrie G, Mayer C, Hold GL, Thomson J, Fyfe N, Hope M, Mowat NA, et al: The inflammatory microenvironment in colorectal neoplasia. PLoS One 6: e15366, 2011.

30. Dong H, Zhu G, Tamada K and Chen L: B7-H1, a third member of the B7 family, co-stimulates T-cell proliferation and interleukin-10 secretion. Nat Med 5: 1365-1369, 1999.

31. Le DT, Uram JN, Wang H, Bartlett BR, Kemberling H, Eyring AD, Skora AD, Luber BS, Azad NS, Laheru D, et al: PD-1 blockade in tumors with mismatch-repair deficiency. New Engl J Med 372: 2509-2520, 2015.

32. Page DB, Postow MA, Callahan MK, Allison JP and Wolchok JD: Immune modulation in cancer with antibodies. Annu Rev Med 65: 185-202, 2014.

33. Yagyuu T, Hatakeyama K, Imada M, Kurihara M, Matsusue Y, Yamamoto K, Obayashi C and Kirita T: Programmed death ligand 1 (PD-L1) expression and tumor microenvironment: Implications for patients with oral precancerous lesions. Oral Oncol 68: 36-43, 2017.

34. Hatam LJ, DeVoti JA, Rosenthal DW, Lam F, Abramson AL, Steinberg BM and Bonagura VR: Immune suppression in premalignant respiratory papillomas: enriched functional CD4+Foxp3+ regulatory $\mathrm{T}$ cells and PD-1/PD-L1/L2 expression. Clin Cancer Res 18: 1925-1935, 2012.

35. Miller TJ, McCoy MJ, Hemmings C, Bulsara MK, Iacopetta B and Platell CF: Objective analysis of cancer stem cell marker expression using immunohistochemistry. Pathology 49: 24-29, 2017.

36. McCoy MJ, Hemmings C, Miller TJ, Austin SJ, Bulsara MK, Zeps N, Nowak AK, Lake RA and Platell CF: Low stromal Foxp3+ regulatory T-cell density is associated with complete response to neoadjuvant chemoradiotherapy in rectal cancer. Br J Cancer 113: 1677-1686, 2015.
37. Lee SJ, Jang BC, Lee SW, Yang YI, Suh SI, Park YM, Oh S, Shin JG, Yao S, Chen L and Choi IH: Interferon regulatory factor-1 is prerequisite to the constitutive expression and IFN-gamma-induced upregulation of B7-H1 (CD274). FEBS Lett 580: 755-762, 2006.

38. Anyaegbu CC, Garrett K, Hemmings C, Lee-Pullen TF and McCoy MJ: Immunohistochemical detection of PD-L1 for research studies: which antibody and what protocol? Pathology 49: 427-430, 2017.

39. Ribas A and Hu-Lieskovan S: What does PD-L1 positive or negative mean? J Exp Med 213: 2835-2840, 2016.

40. Li Y, Liang L, Dai W, Cai G, Xu Y, Li X, Li Q and Cai S: Prognostic impact of programed cell death-1 (PD-1) and PD-ligand 1 (PD-L1) expression in cancer cells and tumor infiltrating lymphocytes in colorectal cancer. Mol Cancer 15: 55, 2016.

41. Lee KS, Kwak Y, Ahn S, Shin E, Oh HK, Kim DW, Kang SB, Choe G, Kim WH and Lee HS: Prognostic implication of CD274 (PD-L1) protein expression in tumor-infiltrating immune cells for microsatellite unstable and stable colorectal cancer. Cancer Immunol Immunother 66: 927-939, 2017.

42. Zhong F, Cheng X, Sun S and Zhou J: Transcriptional activation of PD-L1 by Sox 2 contributes to the proliferation of hepatocellular carcinoma cells. Oncol Rep 37: 3061-3067, 2017.

43. Wang T, Ong CW, Shi J, Srivastava S, Yan B, Cheng CL, Yong WP, Chan SL, Yeoh KG, Iacopetta B and Salto-Tellez M: Sequential expression of putative stem cell markers in gastric carcinogenesis. Br J Cancer 105: 658-665, 2011.

44. de Sousa e Melo F, Kurtova AV, Harnoss JM, Kljavin N, Hoeck JD, Hung J, Anderson JE, Storm EE, Modrusan Z, Koeppen H, et al: A distinct role for $\mathrm{Lgr}^{+}$stem cells in primary and metastatic colon cancer. Nature 543: 676-680, 2017.

This work is licensed under a Creative Commons Attribution-NonCommercial-NoDerivatives 4.0 International (CC BY-NC-ND 4.0) License. 